\title{
PENGUJIAN EKSPERIMENTAL DAN SIMULASI ANSYS PERFORMANSI POMPA SENTRIFUGAL RANGKAIAN SERI DAN PARALEL
}

\author{
Adam Hafizar Pohan \\ Program Studi Teknik Mesin, Fakultas Teknik, Universitas Sumatra Utara, \\ Jalan Almamater Kampus USU, Medan 20155 \\ Email: hafizar.pohan@gmail.com
}

\begin{abstract}
This study was conducted to identify the performance of centrifugal pump series configuration and parallel configuration experimentally and Ansys simulation. In the previous study, the performance of centrifugal pumps was calculated by varying the valve opening. In this study researchers varied motor rotation of $1000 \mathrm{rpm}, 1200 \mathrm{rpm}, 1400 \mathrm{rpm}, 1600 \mathrm{rpm}$ and $1800 \mathrm{rpm}$ with open valve 100\%. The results show that series configuration has higher head value than parallel configuration. While the parallel configuration has a higher capacity value than the series configuration. The highest pump efficiency for this pump performance test is in series configuration of $1800 \mathrm{rpm}$ is $83.4 \%$ for experimental and $85 \%$ for simulation. While the lowest pump efficiency is in parallel configuration pumps of $1800 \mathrm{rpm}$ with an efficiency $14.1 \%$ for experimental and $15.5 \%$ for simulation.
\end{abstract}

Key Words : Centrifugal pump, performance, efficiency

\section{PENDAHULUAN}

Pompa adalah salah satu jenis mesin fluida yang berfungsi untuk memberikan energi kepada fluida, dimana fluida adalah zat cair, sehingga zat cair tersebut dapat dipindahkan dari suatu tempat ke tempat lain. Dalam operasinya pompa perlu digerakkan oleh suatu penggerak mula, dalam hal ini dapat digunakan motor listrik maupun motor torak. Dalam menjalankan fungsinya tersebut, pompa mengubah energi gerak poros untuk menggerakkan sudu-sudu (impeller) menjadi energi tekanan pada fluida.

Salah satu jenis pompa yang banyak digunakan adalah pompa sentrifugal.
Pompa sentrifugal Merupakan pompa yang sangat umum digunakan untuk pemompaan fluida seperti air, minyak dan lain - lain di berbagai industri. Dalam dunia industri, mengetahui performansi mesin seperti pompa sangat diperlukan. Beberapa parameter yang diperlukan untuk mengetahui performansi pompa yaitu kapasitas, head, daya dan efisiensi. Dari parameter tersebut maka dapat diketahui apakah pompa tersebut masih mampu mengalirkan kapasitas yang sesuai kebutuhan atau tidak, mengetahui kondisi pompa yang masih bekerja dengan kondisi optimal atau tidak dan menetapkan waktu untuk melakukan pemeliharaan seperti 
penggantian komponen yang sudah rusak pada pompa tersebut.

Oleh karena itu maka penulis tertarik untuk mengidentifikasi secara eksperimental dan komputasi performansi pompa sentrifugal rangkaian seri dan rangkaian paralel dengan menggunakan perangkat lunak (software) Ansys Workbench.

\section{TINJAUAN PUSTAKA}

Pompa adalah salah satu jenis mesin fluida yang berfungsi untuk memberikan energi kepada fluida, dimana fluida adalah zat cair, sehingga zat cair tersebut dapat dipindahkan dari suatu tempat ke tempat lain. Dalam operasinya pompa perlu digerakkan oleh suatu penggerak mula, dalam hal ini dapat digunakan motor listrik maupun motor torak. Dalam menjalankan fungsinya tersebut, pompa mengubah energi gerak poros untuk menggerakkan sudu-sudu (impeller) menjadi energi tekanan pada fluida.

$$
\text { Industri - industri banyak }
$$

menggunakan pompa sebagai salah satu peralatan bantu yang penting untuk menyuplai air agar dapat melakukan proses produksi. Sebagai contoh yaitu pada pembangkit listrik tenaga uap, pompa digunakan untuk menyuplai air ke dalam boiler, ke instalasi - instalasi yang membutuhkan air. Pompa juga banyak digunakan untuk mensirkulasi air atau minyak pelumas sebagai pendingin mesinmesin di industri. Pompa juga dipakai pada pesawat terbang yaitu sebagai pompa hidrolik, bahan bakar dan lain sebagainya.

Untuk rumus dalam pengujian ini adalah sebagai berikut:

1. Head Total

Untuk Pompa Seri :

$$
\mathrm{H}=\left(\mathrm{hz}+\Delta \mathrm{hp}+\mathrm{hl}+\mathrm{v}^{2} / 2 \mathrm{~g}\right)(\mathrm{m})
$$

Untuk Pompa Paralel :

$$
\mathrm{H}=1 / 2\left(\mathrm{hz}+\Delta \mathrm{hp}+\mathrm{hl}+\mathrm{v}^{2} / 2 \mathrm{~g}\right)(\mathrm{m})
$$

Kecepatan Air Di Dalam Pipa :

$$
\mathrm{V}=\mathrm{Q} / \mathrm{A}
$$

Head Statis :

$$
\mathrm{hz}=(\mathrm{hd}+\mathrm{hs})_{1}+(\mathrm{hd}+\mathrm{hs})_{2}(\mathrm{~m})
$$

Head Kerugian :

$$
\mathrm{hl}=(\mathrm{hfg}+\mathrm{hfe}+\mathrm{hfv})
$$

Head Kerugian Gesek Pipa:

$$
h_{f g}=\frac{10,666 \times Q^{1,85}}{C^{1,85} \times D^{4,85}} \times L
$$

Head Kerugian Belokan Pipa :

$$
\begin{gathered}
H_{f e}=f \frac{v^{2}}{2 g} \\
f=0,131+1,847\left(\frac{D}{2 R}\right)^{3,5}\left(\frac{\theta}{90}\right)^{0,5}
\end{gathered}
$$

Head Kerugian Pada Katup:

$$
H_{f v}=f \frac{v^{2}}{2 g}
$$

2. Kapasitas Aliran

$$
Q=C_{e} \cdot \frac{8}{15} \cdot \sqrt{2 g} \cdot \tan \frac{\theta}{2} \cdot h^{5 / 2}
$$

3. Laju Aliran Massa

4. Daya Pompa

$$
\dot{m}=\rho . Q
$$

$$
\mathrm{Pw} \quad=\rho g Q H
$$

5. Efisiensi Pompa

$$
\eta \mathrm{p}=\frac{P w}{P} \times 100 \%
$$

\section{METODE PENELITIAN}


Penelitian dilakukan pada pompa yang disusun secara seri dan paralel dengan memvariasikan putaran motor yaitu 1000 rpm, 1200 rpm, 1400 rpm, 1600 rpm, dan $1800 \mathrm{rpm}$. Alat penelitian untuk pengujian performansi pompa ini adalah pompa sentrifugal rangkaian seri dan rangkaian paralel. Alat ini juga dilengkapi pengukur head suction, head discharge, putaran motor dan kapasitas aliran.

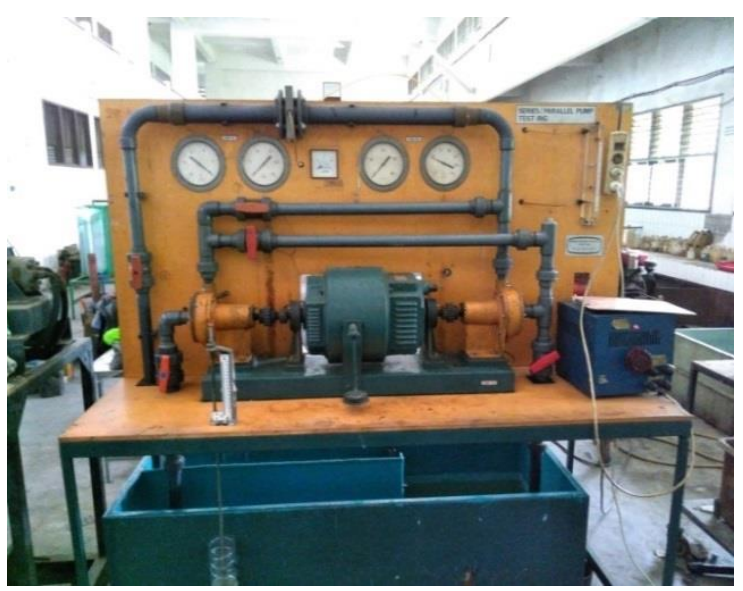

Gambar 1. Pompa Sentrifugal Seri/Paralel

Spesifikasi :

Type pompa : Open Impeller Sentrifugal

Motor : : Paralel speed 0 - 2900

rpm

Tegangan : 220 volt

Frekuensi $\quad: 50 \mathrm{~Hz}$

Daya $\quad: 2,2 \mathrm{Kw}$

Tahap Pengujian :

Pompa rangkaian seri

1. Posisikan katup 1, katup 3 dan katup 5 dalam posisi terbuka, sedangkan katup 2 dan katup 4 dalam posisi tertutup.

2. Hidupkan switch pada posisi ON.
3. Atur putaran motor sebesar $1000 \mathrm{rpm}$, $1200 \mathrm{rpm}, 1400 \mathrm{rpm}, 1600 \mathrm{rpm}$ dan $1800 \mathrm{rpm}$.

4. Amati dan catat parameter yang diperlukan disetiap perubahan putaran motor yang dilakukan.

Pompa rangkaian Paralel

1. Posisikan katup 1, katup 2, katup 4 dan katup 5 dalam posisi terbuka, sedangkan katup 3 dalam posisi tertutup.

2. Hidupkan switch pada posisi ON.

3. Atur putaran motor sebesar $1000 \mathrm{rpm}$, $1200 \mathrm{rpm}, 1400 \mathrm{rpm}, 1600 \mathrm{rpm}$ dan $1800 \mathrm{rpm}$.

4. Amati dan catat parameter yang diperlukan disetiap perubahan putaran motor yang dilakukan.

$>$ Pembuatan model CAD.

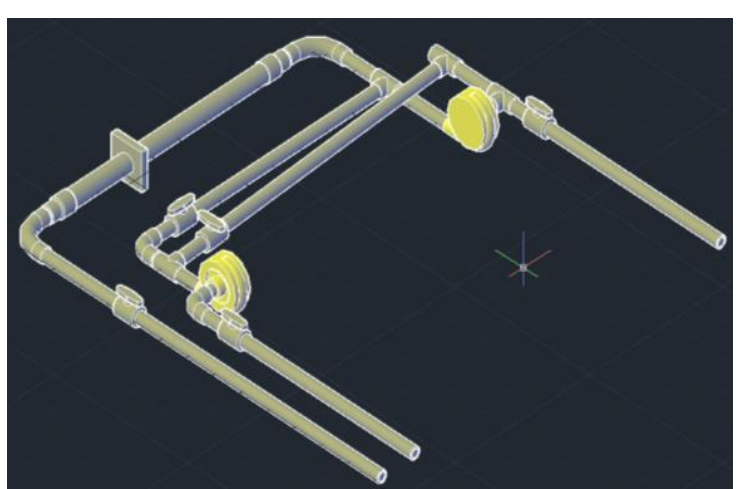

Gambar 2. Pembuatan Model CAD

Proses Meshing. 


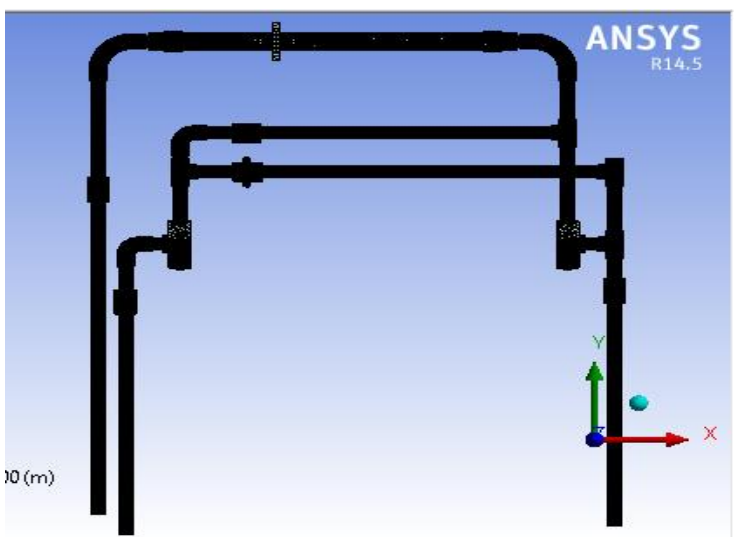

Gambar 3. Proses Meshing

Proses Simulasi CFD.

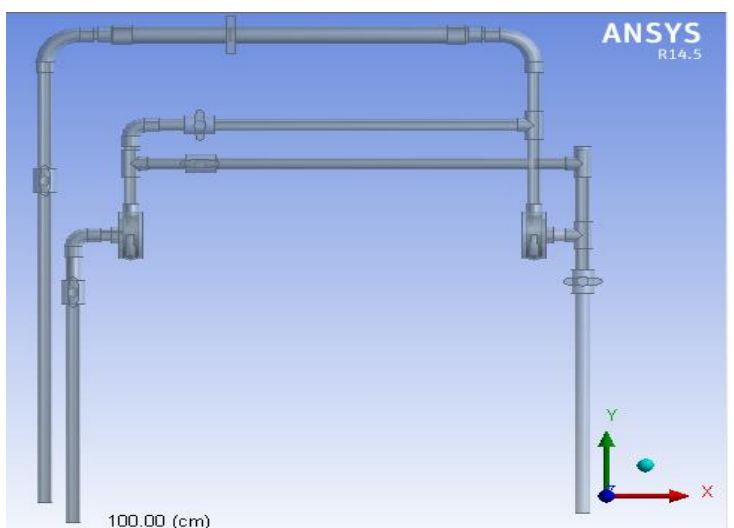

Gambar 4. Proses Simulasi CFD

\section{HASIL DAN PEMBAHASAN}

Dari data pengujian yang dilakukan, diperoleh data berupa head suction, head discharge dan ketinggian air untuk setiap variasi putaran untuk rangkaian seri dan paralel

Tabel 1. Hasil pengujian rangkaian seri

\begin{tabular}{|c|c|c|c|c|c|}
\hline \multirow{2}{*}{$\mathrm{n}(\mathrm{rpm})$} & \multicolumn{2}{|c|}{ Pompa 1} & \multicolumn{2}{|c|}{ Pompa 2} & \multirow{2}{*}{$\mathrm{h}_{\mathrm{W}}(\mathrm{m})$} \\
\cline { 2 - 5 } & $\mathrm{Hs}_{1}(\mathrm{~m})$ & $\mathrm{Hd}_{1}(\mathrm{~m})$ & $\mathrm{Hs}_{2}(\mathrm{~m})$ & $\mathrm{Hd}_{2}(\mathrm{~m})$ & \\
\hline 1000 & 0,72 & 0 & $-1,5$ & 0 & 0,105 \\
\hline 1200 & 0,88 & 0 & $-1,78$ & 0 & 0,111 \\
\hline 1400 & 1,22 & 0 & $-1,96$ & 0 & 0,118 \\
\hline 1600 & 1,46 & 0 & $-2,06$ & 0,18 & 0,122 \\
\hline 1800 & 1,8 & 0 & $-2,5$ & 0,76 & 0,126 \\
\hline
\end{tabular}

Tabel 2. Hasil pengujian rangkaian paralel
ISSN 1411 - 5247

\begin{tabular}{|c|c|c|c|c|c|}
\hline \multirow{2}{*}{$\mathrm{n}(\mathrm{rpm})$} & \multicolumn{2}{|c|}{ Pompa 1} & \multicolumn{2}{|c|}{ Pompa 2 } & \multirow{2}{*}{$\mathrm{h}_{\mathrm{N}}(\mathrm{m})$} \\
\cline { 2 - 5 } & $\mathrm{Hs}_{1}(\mathrm{~m})$ & $\mathrm{Hd}_{1}(\mathrm{~m})$ & $\mathrm{Hs}_{2}(\mathrm{~m})$ & $\mathrm{Hd}_{2}(\mathrm{~m})$ & \\
\hline 1000 & 0,50 & 0 & $-2,00$ & 0 & 0,112 \\
\hline 1200 & 0,70 & 0 & $-2,42$ & 0 & 0,118 \\
\hline 1400 & 0,82 & 0,18 & $-2,90$ & 0,12 & 0,125 \\
\hline 1600 & 1,00 & 1,08 & $-3,50$ & 0,86 & 0,130 \\
\hline 1800 & 1,32 & 1,82 & $-4,18$ & 1,82 & 0,135 \\
\hline
\end{tabular}

Dari data hasil pengujian maka dapat dilakukan perhitungan performansi pompa. Setelah dilakukan perhitungan performansi pompa maka dapat diperoleh data seperti kapasitas, head, daya pompa dan efisiensi pompa.

Tabel 3. Hasil perhitungan performansi pompa rangkaian seri

\begin{tabular}{|c|c|c|c|c|c|c|}
\hline $\begin{array}{c}\text { Putaran } \\
(\mathrm{rpm})\end{array}$ & $\begin{array}{c}\mathrm{Q}(\mathrm{m} 3 / \mathrm{s}) \\
10^{-2}\end{array}$ & $\mathrm{v}(\mathrm{m} / \mathrm{s})$ & $\mathrm{m}(\mathrm{kg} / \mathrm{s})$ & $\begin{array}{c}\text { Head } \\
\text { Total }(\mathrm{m})\end{array}$ & $\begin{array}{c}\text { Daya Pompa } \\
(\mathrm{kw})\end{array}$ & $\begin{array}{c}\text { Efisiensi } \\
(\%)\end{array}$ \\
\hline 1000 & 0,487 & 6,05 & 4,85 & 9,4 & 0,4 & 20,3 \\
\hline 1200 & 0,559 & 6,95 & 5,57 & 12,6 & 0,7 & 31,2 \\
\hline 1400 & 0,651 & 8,10 & 6,49 & 17,0 & 1,1 & 49,3 \\
\hline 1600 & 0,708 & 8,81 & 7,05 & 20,6 & 1,4 & 64,7 \\
\hline 1800 & 0,767 & 9,55 & 7,64 & 24,7 & 1,9 & 84,3 \\
\hline
\end{tabular}

Tabel 4. Hasil perhitungan performansi pompa rangkaian paralel

\begin{tabular}{|c|c|c|c|c|c|c|}
\hline $\begin{array}{c}\text { Putaran } \\
(\mathrm{rpm})\end{array}$ & $\begin{array}{c}\mathrm{Q}(\mathrm{m} 3 / \mathrm{s}) \\
10^{-2}\end{array}$ & $\mathrm{v}(\mathrm{m} / \mathrm{s})$ & $\mathrm{m}(\mathrm{kg} / \mathrm{s})$ & $\begin{array}{c}\text { Head } \\
\text { Total }(\mathrm{m})\end{array}$ & $\begin{array}{c}\text { Daya Pompa } \\
(\mathrm{kw})\end{array}$ & $\begin{array}{c}\text { Efisiensi } \\
(\%)\end{array}$ \\
\hline 1000 & 0,572 & 7,11 & 5,69 & 5,5 & 0,3 & 14,1 \\
\hline 1200 & 0,651 & 8,10 & 6,49 & 7,2 & 0,5 & 20,9 \\
\hline 1400 & 0,752 & 9,36 & 7,49 & 9,8 & 0,7 & 32,7 \\
\hline 1600 & 0,830 & 10,32 & 8,27 & 12,6 & 1,0 & 46,4 \\
\hline 1800 & 0,912 & 11,35 & 9,08 & 15,8 & 1,4 & 64,0 \\
\hline
\end{tabular}

Dari hasil simulasi CFD maka diperoleh data pada tabel berikut ini :

Tabel 5. Hasil simulasi CFD performansi pompa rangkaian seri

\begin{tabular}{|c|c|c|c|c|c|}
\hline $\begin{array}{c}\text { Putaran } \\
(\mathrm{rpm})\end{array}$ & $\begin{array}{c}\mathrm{Q}(\mathrm{m} 3 / \mathrm{s}) \\
10^{-2}\end{array}$ & $\mathrm{v}(\mathrm{m} / \mathrm{s})$ & $\begin{array}{c}\text { Head Total } \\
(\mathrm{m})\end{array}$ & $\begin{array}{c}\text { Daya Pompa } \\
(\mathrm{kw})\end{array}$ & $\begin{array}{c}\text { Efisiensi } \\
(\%)\end{array}$ \\
\hline 1000 & 0,513 & 6,43 & 10,5 & 0,53 & 24,0 \\
\hline 1200 & 0,562 & 7,85 & 13,7 & 0,75 & 34,2 \\
\hline 1400 & 0,669 & 8,39 & 18,1 & 1,18 & 53,7 \\
\hline 1600 & 0,713 & 8,84 & 20,7 & 1,44 & 65,4 \\
\hline 1800 & 0,772 & 9,68 & 24,8 & 1,87 & 85,0 \\
\hline
\end{tabular}

Tabel 6. Hasil simulasi CFD performansi pompa rangkaian paralel 


\begin{tabular}{|c|c|c|c|c|c|}
\hline $\begin{array}{c}\text { Putaran } \\
(\mathrm{rpm})\end{array}$ & $\begin{array}{c}\mathrm{Q}(\mathrm{m} 3 / \mathrm{s}) \\
10^{-2}\end{array}$ & $\mathrm{v}(\mathrm{m} / \mathrm{s})$ & $\begin{array}{c}\text { Head Total } \\
(\mathrm{m})\end{array}$ & $\begin{array}{c}\text { Daya Pompa } \\
(\mathrm{kw})\end{array}$ & $\begin{array}{c}\text { Efisiensi } \\
(\%)\end{array}$ \\
\hline 1000 & 0,588 & 7,37 & 5.9 & 0.34 & 15.5 \\
\hline 1200 & 0,655 & 8,21 & 7.4 & 0.47 & 21.5 \\
\hline 1400 & 0,757 & 9,49 & 10 & 0,74 & 33,5 \\
\hline 1600 & 0,851 & 10,67 & 13,3 & 1,11 & 50,3 \\
\hline 1800 & 0,918 & 11,50 & 16,1 & 1,44 & 65,6 \\
\hline
\end{tabular}

Dari data hasil perhitungan performansi pompa dan data hasil simulasi CFD maka diperoleh grafik berikut ini :



Gambar 5. Grafik hubungan kapasitas, head dan putaran

Hubungan anatara kapasitas dan head yang dihitung secara eksperimental bahwa nilai kapasitas dan head akan semakin tinggi seiring dengan semakin besarnya putaran. Nilai kapasitas tertinggi terdapat pada pompa rangkaian paralel pada putaran $1800 \mathrm{rpm}$ yaitu sebesar 0,912 x 10-2 m3/s. Sedangkan Nilai head tertinggi terdapat pada pompa rangkaian seri pada putaran $1800 \mathrm{rpm}$ yaitu sebesar $24,7 \mathrm{~m}$.

Hubungan anatara kapasitas dan head yang didapat dari simulasi CFD pada software Ansys Workbench bahwa nilai kapasitas dan head akan semakin tinggi seiring dengan semakin besarnya putaran. Nilai kapasitas tertinggi terdapat pada pompa rangkaian paralel pada putaran $1800 \mathrm{rpm}$ yaitu sebesar 0,918 x 10-2 m3/s. Sedangkan Nilai head tertinggi terdapat pada pompa rangkaian seri pada putaran $1800 \mathrm{rpm}$ yaitu sebesar $24,8 \mathrm{~m}$.

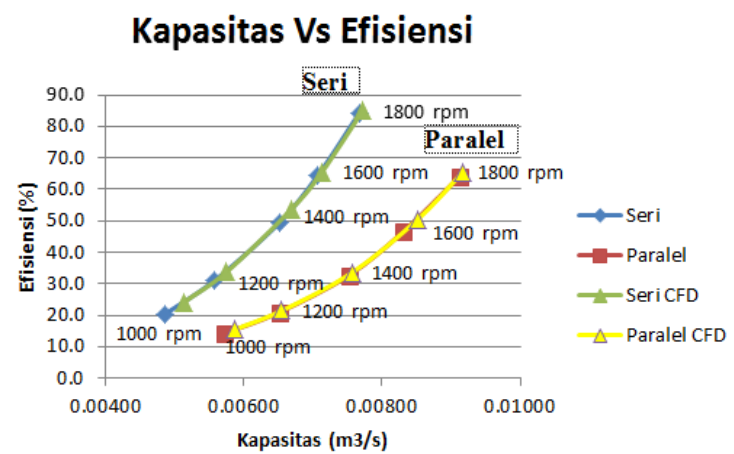

Gambar 6. Grafik hubungan kapasitas, efisiensi dan putaran

Hubungan anatara kapasitas dan efisiensi yang dihitung secara eksperimental bahwa nilai kapasitas dan efisiensi akan semakin tinggi seiring dengan semakin besarnya putaran. Nilai efisiensi tertinggi terdapat pada pompa rangkaian seri pada putaran 1800 rpm yaitu sebesar 84,3\% dengan kapasitas sebesar 0,767 x $10-2 \mathrm{~m} 3 / \mathrm{s}$. Sedangkan Nilai efisiensi terendah terdapat pada pompa rangkaian paralel pada putaran 1000 rpm yaitu sebesar 14,1\% dengan kapasitas sebesar 0,572 x 10-2 m3/s.

Hubungan anatara kapasitas dan head yang didapat dari simulasi CFD pada software Ansys Workbench bahwa nilai kapasitas dan efisiensi akan semakin tinggi seiring dengan semakin besarnya putaran. Nilai 
efisiensi tertinggi terdapat pada pompa rangkaian seri pada putaran $1800 \mathrm{rpm}$ yaitu sebesar $85 \%$ dengan kapasitas sebesar $0,918 \times 10-2 \mathrm{~m} 3 / \mathrm{s}$. Sedangkan Nilai efisiensi terendah terdapat pada pompa rangkaian paralel pada putaran $1000 \mathrm{rpm}$ yaitu sebesar $15,5 \%$ dengan kapasitas sebesar $0,588 \times 10-2 \mathrm{~m} 3 / \mathrm{s}$.

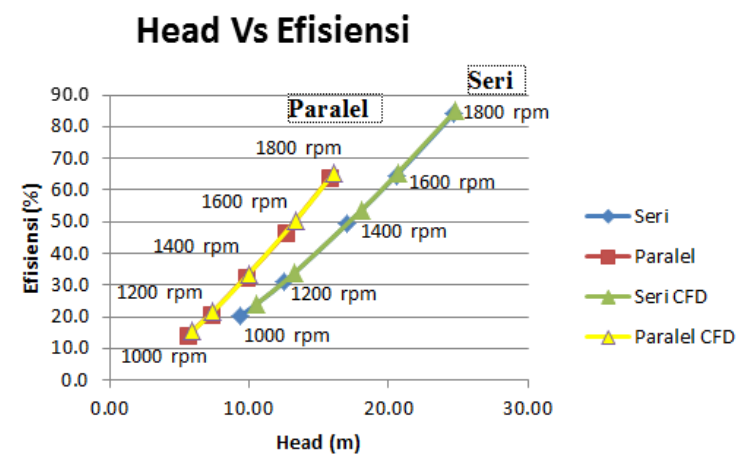

Gambar 7. Grafik hubungan head, efisiensi dan putaran

Hubungan anatara head dan efisiensi yang dihitung secara eksperimental bahwa nilai kapasitas dan efisiensi akan semakin tinggi seiring dengan semakin besarnya putaran. Nilai efisiensi tertinggi terdapat pada pompa rangkaian seri pada putaran 1800 rpm yaitu sebesar $84,3 \%$ dengan total head sebesar 24,73 m. Sedangkan Nilai efisiensi terendah terdapat pada pompa rangkaian paralel pada putaran $1000 \mathrm{rpm}$ yaitu sebesar $14,1 \%$ dengan total head sebesar $5,55 \mathrm{~m}$.

Hubungan anatara kapasitas dan head yang didapat dari simulasi CFD pada software Ansys Workbench bahwa nilai kapasitas dan efisiensi akan semakin tinggi seiring dengan semakin besarnya putaran. Nilai efisiensi tertinggi terdapat pada pompa rangkaian seri pada putaran $1800 \mathrm{rpm}$ yaitu sebesar $85 \%$ dengan total head sebesar 24,78 m. Sedangkan Nilai efisiensi terendah terdapat pada pompa rangkaian paralel pada putaran 1000 rpm yaitu sebesar $15,5 \%$ dengan total head sebesar $5,94 \mathrm{~m}$.

\section{KESIMPULAN}

Berdasarkan penelitian dan analisa yang telah dilakukan, maka dapat disimpulkan sebagai berikut :

1. Nilai kapasitas yang tertinggi yang diperoleh dari eksperimental dan komputasi terdapat pada pompa rangkaian paralel pada putaran 1800 rpm dengan nilai kapasitas sebesar 0,912 x 10-2 m3/s untuk eksperimental dan sebesar $0,918 \times 10-2 \mathrm{~m} 3 / \mathrm{s}$ untuk komputasi. Sedangkan Nilai head tertinggi yang diperoleh dari eksperimental dan komputasi terdapat pada pompa rangkaian seri pada putaran $1800 \mathrm{rpm}$ dengan nilai head sebesar 24,73 m untuk eksperimental dan sebesar 24,78 m untuk komputasi.

2. Pada pompa paralel memiliki kapasitas terbesar karena terdapat dua saluran hisap. Fluida yang dihisap melalui pompa 1 ditambah dengan fluida yang dihisap dari saluran pompa 2 sehingga menghasilkan kapasitas yang besar. Sedangkan pada pompa seri memiliki 
head terbesar karena fluida mengalami dua kali kerja. Head tekanan yang dihasilkan pompa 1 mendapat tambahan head pada pompa 2 sehingga head total menjadi besar.

3. Nilai efisiensi pompa tertinggi yang diperoleh dari eksperimental dan komputasi terdapat pada pompa rangkaian seri dengan efisiensi sebesar $83,4 \%$ untuk eksperimental dan $85 \%$ untuk komputasi. Sedangkan efisiensi pompa terendah terdapat pada pompa rangkaian paralel dengan efisiensi sebesar $14,1 \%$ untuk eksperimental dan $15,5 \%$ untuk komputasi.

\section{Daftar Pustaka}

Sularso, Haruo Tahara. 1994. Pompa dan Kompresor. Jakarta : Pradnya Paramita.

Astu Pudjanarsa, Djati Nursuhud. 2006. Mesin Konversi Energi. Yogyakarta : Andi.

Yunus A. Cengel, John M. Cimbala .2006. Fluid Mechanics : Fundamentals \& Applications. New York. McGrawHill

Hamsi, Alfian. 2002. Panduan Praktikum Pompa Sentrifugal. Teknik Universitas Sumatera Utara

Ambarita, Himsar. 2010. Persamaan Pembentuk Aliran. Teknik Mesin Universitas Sumatera Utara 